\title{
Consumer's attitudes and willingness-to-pay for Green food in Beijing
}

\author{
Wei Xia, Yinchu Zeng \\ School of Agricultural Economics and Rural Development, Renmin University of China
}

\begin{abstract}
A survey in random-selected supermarkets in Beijing, the capital city of China, is reported to identify the attitudes and perceptions of consumers toward green-labeled milk, as well as their willingness to pay (WTP) for it, and to determine the factors that affect their WTP. The study reveals that the majority of households are quite familiar with green food and most of them take positive attitudes towards them, while with certain anxieties. Both remarkable preferences for location and branding in milk purchase and neglects for quality and safety are found in the consumers' purchase pattern. The willingness to pay are concentrated in a range of 5 - 10 percent premium than ordinary milk, and age, the perception of green food and the access to information serve as the main factors influencing WTP value.
\end{abstract}

Keywords food safety, green food, consumer behavior, willingness to pay

\section{Introduction}

Consumer's concern and awareness of food quality have undoubtedly been fuelled by large increases in real per capita income, development of technology and medicine, as well as food safety scares of recent years. Producers and industry associations will not voluntarily label how safe the foodstuffs really are in the market, and therefore, asymmetric information of products happens, blocking consumer's knowledge of real food quality and safety (Caswell and Mojduszka, 1996).Thus, it is government's responsibility to afford a system supervising on food detection and certification to provide consumers an access to food safety information (Choi and Jensen, 1991).

Green food certification, a system to confirm the conformity of certain products to a set of standards, may build trust between parties involved. Consumers have a much more comprehensive understanding of green production process, compared with pesticide-reduced and organic food, since it is the earliest food quality standard adopted in China(Wang,2003; Zhou,2004; Zhang,2004; Chang\& Li,2005,Zeng\&Xia,2005). Green operators produce, handle and process in a way with strong emphasis on environmental concerns, and the costs of green food thus are much higher than ordinaries (Zhang, 2001).It has implications for farmers, food producers, distributors, and consumers. Farmers benefit from having a better understanding of the value of their products and therefore are better able to determine how to maximize profits. Companies benefit by being able to determine the economic gain or loss associated with labeling green products. Food distributors are better able to stock this kind of goods to satisfied with consumer's demand Consumers benefit by having choices that maximize their utility (Kolodinsky, DeSisto and Wang, 2003).

Recently, plenty of researches have being taken on examining determinants of consumer's WTP for food safety and have come to a common finding that the primary factors tender to be consumer's socio-economic characteristics, consumer's perception of food risk, and consumer's purchasing experience. Following these researches, much more attention is paid to the relationship among consumer's perception, consumer's behavior and consumer's willingness-to-pay, which brings intensive arguments on the explanations of findings, the relationship of dependent and independent variables, a field for further discussion.

Several studies in China, for the present, concentrate on study of consumer attitudes and purchase behaviors. Limited efforts, nevertheless, have been done on the valuation of WTP and the determinants (Wang,2003; Zhou,2004;Zhou, 2004;Zeng\& Xia,2005; Chen 2006),except for Chang\& Li(2005) and Zhou\&Peng(2006).Chang\& Li(2005) discussed the relationship between consumer's WTP and perception as well as confidence in green vegetables with a bivariate correlation. The result indicates that consumer's confidence in green vegetables attributes positively to his/her WTP. However, the awareness of green foods does not mean good knowledge and fine perception, not sufficiently to support the conclusions. A semi-double bounded dichotomous choice model was employed by Zhou\&Peng(2006) to value consumer's WTP for pesticide-reduced foods and comes to a conclusion that consumer is willing to pay $335 \%$ premier which was significant related to price, city scope, household with children, awareness of health risk, family scale, household income and suffering index of pesticide. 
Focusing on green labeled milk, a survey in random-selected supermarkets in Beijing was carried out on May, 2005. The aim of the study is to shed light on consumer's perception and their willingness to pay with regard to green foods. More specifically, the objectives of the research are:

- To identify how much consumers are willing to pay for green labeled foods in Beijing;

- To attempt to model the most important factors affecting consumer's wtp for green labeled foods;

- To identify how consumer's perception and attitudes impact consumer's wtp with respect to green labeled food.

To address these issues systematically, a theoretical model integrating consumer's stated willingness to pay with their perception of green foods based on Millock(2003) is developed.

\section{Theoretical Framework of WTP Analysis}

According to consumer behavior theory, consumers make the decision to balance the marginal health utility and marginal price of one unit of quality-improved food. The marginal health utility lies on the awareness and perception of risks, which are determined by consumer's socio-economic characteristics, learning ability and exposure levels to food-borne hazards(Eom 1995,Blend and Ravensway 1999).

Based on the framework of Millock(2003),combined with Bonti-Ankomah\& Yiridoe (2006) 's analyzing steps, a simplified theoretical frame for WTP analysis is put forward in Figure 1. Consumers and markets are two independent but interactive subjects under the frame. Our research follow with classical consumer behavior theory: perception determines behavior and behavior determines WTP. In terms of Lavidge\&Steiner(1961)'s “Hierarchy of effects"-model, consumer's mental decision is divided into three mental components- Knowledge, Attitude and Intention, which are all responding to commercial or non-commercial information and influence their willingness to pay. Willingness-to-buy provides the threshold of entering the market, which is the previous step before purchasing(Soler,2004).Purchase behavior reflects the real wtp and gains positive or negative experiences which will reversely affect consumer's WTP in future. Consumer's characteristics influence all decision process. Therefore, it is meaningful to explore consumer's individual characteristics for the division of green/organic food markets.

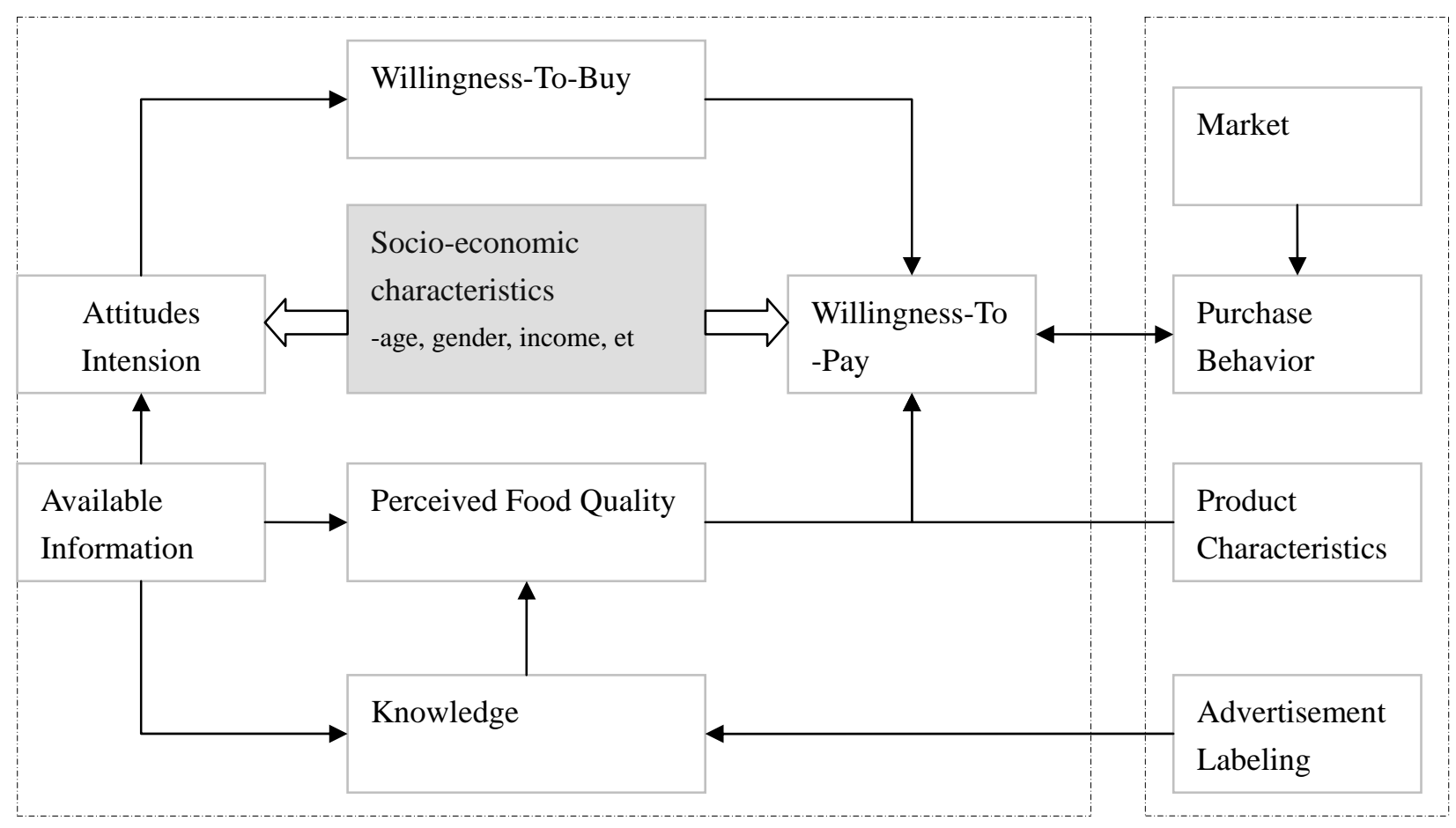

Figure1. Framework consumer behavior towards food Based on Millock(2003). 


\section{Experimental Design and Descriptive Characteristics}

\section{Experiment Design}

As Smith (2000) recently pointed out, "Contingent valuation has prompted the most serious investigation of individual preferences ever undertaken in economics." There are continuous and discrete contingent valuation estimates and continuous CV method, exactly the payment card, is employed in this research. The contingent scenery is carried out as follows ${ }^{1}$ :

Suppose you are confronted with two sorts of milk, green labeled or ordinary for your choice in a supermarket. Both of them meet the national quality standard, however, the green labeled milk measures up to green food process standards, which you can identify it by its particular certification logo. If you choose the green ones, please pick the maximizing-premier out in the table:

Table1. Questionnaire of stated WTP for green milk

\begin{tabular}{|c|c|c|c|c|c|c|c|c|}
\hline \multirow{3}{*}{$\begin{array}{l}\text { brand } \\
\text { Yili } \\
(227 \mathrm{ml})\end{array}$} & $\begin{array}{l}\text { Ordinary } \\
\text { Milk } \\
\text { (yuan) }\end{array}$ & \multicolumn{7}{|c|}{ Green labeled milk (yuan) } \\
\hline & \multirow[t]{2}{*}{1.30} & 1.35 & 1.40 & 1.45 & 1.50 & 1.55 & 1.60 & 1.65 \\
\hline & & 1. 70 & 1.75 & 1.80 & 1.85 & 1.90 & & \\
\hline \multirow{2}{*}{$\begin{array}{l}\text { Sanyuan } \\
(250 \mathrm{~m} 1)\end{array}$} & \multirow[t]{2}{*}{1.90} & 1.95 & 2.00 & 2.05 & 2. 10 & 2. 15 & 2.20 & 2.25 \\
\hline & & 2.30 & 2.35 & 2. 40 & 2. 45 & 2.50 & & \\
\hline \multirow{2}{*}{$\begin{array}{l}\text { Mengniu } \\
(227 \mathrm{~m} 1)\end{array}$} & \multirow[t]{2}{*}{1.65} & 1.70 & 1.75 & 1.80 & 1.85 & 1.90 & 1.95 & 2.00 \\
\hline & & 2.05 & 2.10 & 2.15 & 2.20 & 2.25 & & \\
\hline
\end{tabular}

Consumer are informed that the differences between ordinary and green milk from the aspects of safety, environment friendly and animal welfare, especially the recognizable green food logo. We report the real prices of ordinary milk in the supermarket, providing them with a real market decision, to minimize the bias of contingent survey, with the following question:

How much are you willing to pay for green labeled food superlatively?

1) below $5 \%$; 2) 6-10\% ;3)11-20\%;(4)21-40\%;(5)41-50\%;(6)51-60\%;(7)61-70\% ;

2) $71-80 \% ; 3) 81-90 \%(4)$ above $91 \%$

\section{Procedures and Descriptive Characteristics of the Subjects}

Questionnaires with a little present were distributed to 420 shoppers by six trained interviewers at the entrance and exit to supermarkets and open-door market in April, 2005.Thus a total of 407 questionnaires were returned, for a response rate of $96.9 \%$, after examination according to the certain rules ${ }^{2}$, a subsample of 300 is left. However, this survey technique is likely to be subject to potential bias such as sampling bias (Mithcell and Carson).Table 2 indicates that demographic characteristics of the sample appear to comparable with those of the target population. However, it is more notable that well educated respondents are more predominant in our sample (63.8\%) than in the census study (23.2\%).This also reveals education plays an important role in the perception and acceptance of green food and environmental concepts. Thus, we don't consider the education effect in the latter determinants study.

\footnotetext{
${ }^{1}$ A pre-research had been taken out to identify the range of wtp for green milk, and the price of ordinary milk is the real in the market. Yili, Sanyuan, Mengniu are the three main bands in Beijing.

${ }^{2}$ This was either because the contacted person declined an interview or because the information collected was not complete.
} 
Table2. Comparison of sample characteristics (2004)

\begin{tabular}{|c|c|c|}
\hline & Target Population(Beijing) $^{a}$ & Sample \\
\hline \multicolumn{3}{|l|}{ Age $^{b}$ (class) } \\
\hline Mean & 3.67 & 2.82 \\
\hline Median & 2 & 2 \\
\hline \multicolumn{3}{|l|}{ Gender(percent) } \\
\hline Male & 51.2 & 49.0 \\
\hline Female & 48.8 & 51.0 \\
\hline \multicolumn{3}{|l|}{ Personal Income C (class) } \\
\hline Mean & / & 3.68 \\
\hline Median & / & 4 \\
\hline \multicolumn{3}{|l|}{ Education(percent) } \\
\hline College education and above & 23.2 & 63.8 \\
\hline \multicolumn{3}{|l|}{ Marriage(percent) } \\
\hline married & / & 53.0 \\
\hline
\end{tabular}

\section{Empirical study results}

\section{Consumer's Awareness, Knowledge and Anxiety of Green Foods}

The results of survey on consumer's awareness of green food, in table 3, indicate that the majority were anxious about food safety diseases, which is consistent with Wang(2003) and ZhouJiehong(2004)'s findings in China. Consumers in China commonly feel unsafe about food they eat. With high per capita income, people care more about food safety, nutrition besides food security; at the same time, food safety, as a form of market failure, is sharpening in market economy when food risk issues are frequently exposed in the light of the day.

Consumers are familiar with green food and have a good knowledge of green food as the concept and connotation of 'Green' is widely publicized in China in these 14 years. At the same time, nearly one quarter of consumers misunderstand it as natural food. A certain percent still don't know the exact meaning and certification standards.

Only 49.7 percent of the 300 responders stated they trusted in the current green labeled food (see Table 4), that is to say, quite a lot people are quite doubtful of the quality of green food. This is related with consumer's anxious bout food safety and the faultiness of the certification and surveillance systems which induces actions out of order.

It results in encroachment and counterfeit of green food as some corporations are lack of law consciousness. Some companies make bold to extend the admission range or use the label out of permit time or make an image alike that badly destroy the whole attitude toward green food.

Recently China Green Food Development Center and Beijing Green Food Office did a market research of green food and found that many problems in using of the employment of Green food logo including some cheating actions by one or two brands. Problems ,especially counterfeit and usage out of time limit, are found in Twenty-five of two hundred and forty-three species that counts 9.3percent.Catering to consumers' willingness to buy green food, quit a lot companies skillfully imitating the logo and cheat the consumers who don't carefully identify the logo or can't identify the right ones when purchasing. This kind of green food or false green food are rarely guaranteed which leads to market failure with consumer's doubts of green food after purchasing. 
Table3. Summary of survey results: consumer awareness and knowledge of green foods

\begin{tabular}{|c|c|c|}
\hline Variables & Frequency & Percentage (\%) \\
\hline \multicolumn{3}{|l|}{ Have you heard about green food? } \\
\hline yes & 281 & 93.7 \\
\hline no & 19 & 6.3 \\
\hline \multicolumn{3}{|c|}{$\begin{array}{l}\text { Have you heard about the specific logo green } \\
\text { food? }\end{array}$} \\
\hline yes & 220 & 73.3 \\
\hline no & 80 & 26.7 \\
\hline \multicolumn{3}{|c|}{$\begin{array}{l}\text { Can you tell which one is the right logo of } \\
\text { green food? }\end{array}$} \\
\hline Right & 154 & 51.3 \\
\hline wrong & 146 & 48.7 \\
\hline \multicolumn{3}{|c|}{$\begin{array}{l}\text { Your main access to information for green } \\
\text { food }\end{array}$} \\
\hline Newspaper & 22 & 15.8 \\
\hline Television & 41 & 45.3 \\
\hline Food label & 63 & 29.5 \\
\hline others & 13 & 9.4 \\
\hline \multicolumn{3}{|c|}{$\begin{array}{l}\text { How do you comprehend the standard of green } \\
\text { food? }\end{array}$} \\
\hline food with green color & 19 & 6.3 \\
\hline food free of pesticide and fertilizer & 177 & 59.0 \\
\hline natural food & 73 & 24.3 \\
\hline healthy food & 3 & 1.0 \\
\hline others & 29 & 9.3 \\
\hline
\end{tabular}

Table 4 Summary of survey results: consumer purchase behavior and anxiety

\begin{tabular}{lll}
\hline Variables & Frequency & Percentage \\
\hline Have you ever bought green food? & & \\
yes & 263 & 87.7 \\
no & 37 & 12.3 \\
Do you trust in the green labeled food? & & \\
Definitely yes & 17 & 5.7 \\
Average & 149 & 49.7 \\
Definitely not & 78 & 26.0 \\
Not sure & 56 & 18.6 \\
\hline
\end{tabular}

\section{Consumer's Purchase Behavior Pattern Related to Milk}

Distinct preferences in both bands and locations were found in milk purchase. In the interview, a large quantity of customers mentioned the convenience to purchase milk in a supermarket and strongly emphasized that they are confident in the quality of the products there. Food safety is internalized to supermarket-the large scale detail chain operator. Hence, to confirm consumers' confidence in green foods, supermarkets should administer the legitimacy and availability of green 
labeled foods.

Meanwhile, a strong loyalty on brands also was founded in our research. More than half consumers prefer to buy the brand Mengniu. The frequencies of reasons explaining the preference rank from high to low: Good Taste, Confidence in Brand, Quality, Green Food, Advertisement, Popularity, Well-wrapped. Advertisement, Popularity, Well-wrapped and Confidence in Brand are sorted out to the power of brand. Quality and Green Food stand for food quality and safety. Taste indicates one's purchase habit. What we find is the significant influence of brands on milk purchase. In another words, consumers transfer the fear of food hazards to prominent producers, holding the belief that the prominent producers are more likely to label their products compulsorily as well as voluntarily to maintain the brand value, long term returns, and peculiar characteristics. Nevertheless to maximize the profits, companies and producers are absorbed in certification to attract consumers' attention, and in contrast, they lean towards to ignoring the quality maintenance after certification and overrun the time and object limits of a certain certification. The government should attach more importance to the supervising of large detailers and producers.

Table 5 Summary of survey results: consumer purchase behavior related to milk

\begin{tabular}{lll}
\hline Variables & Frequency & Percentage \\
\hline Expenditure on milk per month & & \\
$<10$ yuan & 11 & 3.7 \\
$10-29$ yuan & 52 & 17.3 \\
$30-49$ yuan & 87 & 29 \\
$50-99$ yuan & 95 & 31.7 \\
$>100$ & 55 & 18.3 \\
Where do you buy milk frequently? & & \\
Supermarket & 250 & 83.3 \\
Retailers & 23 & 7.7 \\
Ordered & 24 & 8 \\
Others & 3 & 1 \\
Do you often buy a certain brand milk? & & \\
Yes & 193 & 64.5 \\
No & 106 & 35.5 \\
Do you trust in the quality of milk at present? & & \\
Definitely yes & 100 & 33.3 \\
Average & 179 & 59.7 \\
Definitely no & 14 & 4.7 \\
indifferent & 7 & 2.3 \\
\hline
\end{tabular}

\section{Consumer's attitudes, behavior and WTP of Green labeled milk}

Most consumers are aware of green labeled milk, and tend to choose green labeled if they were not more expensive than ordinary ones. The cross table analysis indicates that who stated no preference on green labeled or not centralized on the ones who is less worried about milk market. The most common reason for choosing green food is pesticide risk related, about $71.7 \%$,and environmental concern is not a strong motivating for consumers to choose green foods, in contrast with findings in other countries.

Up to $60 \%$ consumers believed it is necessary for green food a bit more expensive than ordinary ones and half of consumers' wtps centralized between 6-10\%, comparable with the average market premier $8 \%$, leading to a conclusion that consumer's wtp equals to the value of the real premier( Ravenswaay 1991; Eom 1995). 
Table6. Summary of survey results: consumer attitudes and willingness-to-pay for Green labeled milk

\begin{tabular}{lll}
\hline Variables & Frequency & Percentage \\
\hline $\begin{array}{l}\text { If your can tell the green milk from ordinary } \\
\text { ones, will you choose it at the same price? }\end{array}$ & 231 & 77.3 \\
yes & 4 & 1.3 \\
no & 64 & 21.4 \\
indifferent & & \\
The reason you choose the green ones: & 170 & 71.7 \\
Pesticide-reduced,safe & 21 & 8.9 \\
Environmental friendly & 40 & 16.9 \\
Nutritional & 6 & 2.5 \\
Do you agree that green food's price is supposed & & \\
to be higher? & 173 & \\
Yes & 124 & 58.2 \\
No & & 41.8 \\
How much will you to pay more for green & & \\
labeled milk? & 48 & 20.1 \\
$<5 \%$ & 122 & 51 \\
$5-10 \%$ & 41 & 17.2 \\
10-20\% & 18 & 7.5 \\
$20-40 \%$ & 10 & 4.2 \\
\hline >40\% & & \\
\hline
\end{tabular}

What determines consumer's willingness to pay for green labeled milk?

The willingness-to-pay drawn from payment card method severs as dependent variables, divided into six classes ${ }^{3}: 1=0,2=" 1-5 \%$ ", 3=”5-10\%”,4=”10-20\%”, 5=”20-40\%”,6="above 40\%”.Thereby, a ordinal logit model is explored to the Maximum-Likelihood estimation.

Consumer's willingness to pay for green labeled food is supposed to be related with perception of green foods, the access to green food information, willingness-to-buy, gender, age. WTP and independent variables are defined in Table5:

Table7. Variable definition

\begin{tabular}{|c|c|c|c|}
\hline Variables & Definition & Variables & Definition \\
\hline \multirow[t]{6}{*}{ age } & & ads & $\begin{array}{l}\text { The main access to information is } \\
\text { television }\end{array}$ \\
\hline & $1=$ below 20 & & $1=$ yes \\
\hline & $2={ }^{\prime} 20-30^{\prime}$ & & $2=$ no \\
\hline & $3={ }^{\prime} 30-40^{\prime}$ & Willingess-to-buy & $\begin{array}{l}\text { choose the green milk when they are } \\
\text { at the same price }\end{array}$ \\
\hline & $4=’ 4-40^{\prime}$ & & $1=$ yes \\
\hline & $5=$ "above 50" & & $0=$ others \\
\hline \multirow[t]{3}{*}{ gender } & & knowledge & Perception of the logo \\
\hline & 1=Male & & $1=$ yes \\
\hline & $0=$ Female & & $0=$ no \\
\hline
\end{tabular}

The spss software was used for ordinal logit estimation. Model significance was verified by

\footnotetext{
${ }^{3}$ The consumers who are not willing to pay for green labeled foods, their WTPs equal 0.
} 
calculating the $\chi^{2}$ statistics. Table6 presents the estimation results from the ordinal logit model. Chi-square equal 19.779, significant at 0.006 probability level.

Table8. Regression results of WTP for green labeled milk (ordinal logit analysis)

\begin{tabular}{llll}
\hline & estimate & Wald & sig. \\
\hline age & $2.85^{*}$ & 2.86 & 0.091 \\
age $^{2}$ & $-1.015^{*}$ & 2.825 & 0.093 \\
age $^{3}$ & 0.104 & 2.447 & 0.118 \\
gender & 0.025 & 0.014 & 0.907 \\
knowledge & $0.526^{* *}$ & 4.408 & 0.036 \\
ads & $0.630^{* *}$ & 3.950 & 0.047 \\
Willingness-to & 0.135 & 1.063 & 0.302 \\
-buy & & & \\
\hline
\end{tabular}

Note:*significance at the 0.10 level;**significant at the 0.05 level.

The factors significantly affect value of wtps are age, perception of green foods, TV as the main access to information (Table 8).

A significant inflexion is found in the relationship between age and wtp. The respondents with the highest WTP seem to belong to the youth between 20-30 years old, $6.6 \%$ higher than average WTP. The middle-aged 40-50consumers' wtp is significantly lower than any other other age categories, whereas people above 50 prone to show higher WTPs. If we did not consider the inflexion, the negative sign would show that younger customers were most likely to be willingness to pay more for green food. In contrast, several other researchers (Davidson \& MacKinnon, p.526; Thompson\& Kidwell 1998;Lin \& Li,2005)reported the inverse U-shaped relationship between age and wtp but not statically significant. Lin\&Li found the peaking pot is 31-40, which is supported the statements by Krupnick. This maybe results in the larger proportion of youths, Also, most studies have had very limited participation of older individuals (Krupnick). It probably indicates that green and health food market is determined by the future consumer, the youth, in another perspective. The 20s old youth in Beijing, most of who are well educated, not loyal consumers of a certain band, accept new concepts easily and attempt to the novel alternatives (Tang\&Wan,2003) . It can also be explained by the specific situation in China, the middle aged people are responsible for the education of their children and parents who are probably not guaranteed with insurance, who are more restricted by the budget and more sensitive for price.

Respondents who were heard about the logo of green food tend to pay more. From the correlation analysis, the respondents who were heard about the logo are probably to concern for food risks, be able to distinguish the right logo form others, be aware of the accurate concept of green foods and have the experience of purchasing green food. So the knowledge of green logo can be serve as the responsible variable for consumer's perception and experiences in green foods. This finding support our previous assumption that certification and labeling system will make the credit goods into searching goods by providing consumer's more information (Caswell and Mojduszka 1996. The perceived information and quality, is the genuine factors able to raise consumer's wtp , especially the intellectual consumers (Stiglitz 1989).Several studies have found a positive relationship between consumer purchase behavior and green/ organic food labeling (eg.Chang and Kinnucan, 1991; Kim et al.,1999; Chang\&li,2005 ;Zhou,2006).

The positive and significant sign on Ads indicates that the access to information about green food is vitally important. Costs of time conclude the searching and acknowledging information on health and food issues. Television, the most popular media and primary channel for advertising of green concepts and products, attracts consumer's attention by interesting, intuitional and repeating visual signals and consolidates consumers' confidence in both green foods and distinguished producers. Hence, the consumer who gains food safety information from television tends to pay more. Several studies have focused on how information affects consumer's WTP, most of which find positive conclusion, including with respect to GM foods (Lusk et al, 2004; Marette et al., 2006). 
The effects of gender, and willingness-to-buy which are always concerned with WTP, are not statistically significant. In fact, a great many researches on GM-free or organic food draw the same conclusion（Harris,2000;Soler and M.GiL,2004;Krystallis and Chryssohoidis,2005）.

\section{Conclusions and Discussion}

The purpose of this study is to assess the effects of socio-demographic and perception variables on individual WTP for green food, especially the green labeled milk, to give a further discussion of the relationship between perception and WTP.

The results of this research indicated that respondents to our consumer survey in Beijing, China, generally show great consciousness on food. The majority of households are quite familiar with green food and most of them take positive attitudes towards green foods. About 87.7pecent respondents reported that they had bought green food before, while with certain anxieties, coinciding with other previous researches in China. However, consumers have inconsistent interpretation about what is "organic", up nearly to $30 \%$ mistaking green food for natural food. Most respondents stated they acquired information about organic food from the green logo attached to the products, and television. Logo labeling plays an important role in consumer's knowledge of green food.

Meanwhile, a strong loyalty on brands and preference for purchasing location are also found in our research. Consumers are confident in milk quality at present, and transfer the fear of food hazards to prominent producers and larger supermarkets, holding the belief that the prominent producers and larger supermarkets are more likely to label their products compulsorily as well as voluntarily to maintain the brand values, long term returns, and differential strategies. However, they also expressed anxieties of the quality as more and more food safety issues are coming to the light of the public.

Most consumers are aware of green labeled milk, and tend to choose green labeled if they were not more expensive than ordinary ones. The most popular reason for choosing green labeled food is pesticide-risk or food safety related, about $71.7 \%$. Environmental concern is not a strong motive for consumers to purchase green foods, in contrast with findings in other countries. It seems that people in China tend to pay more for environmental projects, such as recycling or protection for wetland (Wu et al., 2003;Jin\&Wang,2005)but not environmental-friendly food products.

Up to $60 \%$ consumers hold the belief that it is reasonable for green food a bit more expensive than ordinary ones and half of consumers' WTPs centralized between 6-10\%, comparable with the average market premier $8 \%$, leading to a conclusion that average consumer's WTP equals to the value of the real premier and consumers are able to make rational decisions to maximize their utilities. (Ravenswaay, 1991; Eom, 1995). Combining with most of the respondents' experience on purchasing, it also revealed that there is almost no deviation between stated WTP value and the real price they accepted in purchasing based on payment card method.

From a statistical point of view, the results of the ordinal logit model to analyze the main factors influencing consumer's WTPs perform well in terms of theoretical validity. Our priori expectations on the effects of information and consumer's perception on their WTP are conformed by the statistical analysis, with the exception of willingness-to-pay. The factors significantly affect value of WTPs are age, perception of green foods, television as the main access to information. Surprisingly, a significant inflexion is found in the relationship between age and wtp, which is needed further discussion in the future research.

The marketing outlook for green/organic foods in China is optimistic. Younger people are more willing to pay for green foods, in contrast, middle aged around 45-year-old people pay least, which would be improved by intensive promotion of health concept, encouraging middle aged people to borrow from future and invest in their health.

\section{References:}

Brian Harris and David Burress[2000]: Demands for local and organic produce: a brief review of 
the literature, A Report of the Kaw Valley Project for Environmentally Identified Products Bonti-Ankomah Samuel and Yiridoe K Emmanuel [2006]: Organic and conventional Food: A literature Review of the economics of consumer perceptions and preferences.

Caswell, JA and Mojduszka, EM (1996): Using informational labeling to influence the market for quality in food products. American Journal of Agricultural Economics, 78(4), 1248-1253

Choi E.K and H.H [1991] Modeling the Effect of Risk on Food Demand and the Implications for Regulation , Economics of Food Safety, Elsevier Science Publishing Company,P29-44

Caswell, Julie A. Valuing the benefits and costs of improved food safety and nutrition [2002]. The Australian Journal of Agricultural and Resource Economics, vol.42(4): 409-424

Chang, Xiang yang and Li, Xiang[2005]: Empirical study of consumer perception of food safety of vegetables in Nanjing, Consumption Economics, Vol.5:72-76

Chen, Zhi yin[2006]: Analysis of consumer's willingness to buy and purchase behavior towards pesticide-reduced vegetables, Agricultural Technology Economics,Vol.1:68-75

Francisco Soler[2004]Relationship between knowledge and willingness-to-pay for organic food in Spain:evidence from experimental auctions, NJF seminar 366:Food consumption behavior

Gary D.Thompson[1998]:Consumer demands for organic: what we know and what we need to know, American Journal of Agricultural Economics Vol.98,No.90,P1113-1118

Lin Zi wei and Li Ming cong[2005]:Consumers who are willing to pay more for organic products, working paper

Krystallis and Chryssohoidis[2005]:Consumers' willingness to pay for organic food: factors that affect it and variation per organic product type, British-Food-Journal. 2005; 107(4/5): 320-343

Kolodinsky, Jane, DeSisto, P. Thomas and Wang Qing Bin[2003]: Willingness-to-Pay for GE-free Products: A Hedonic Model for Milk with the rBST-free Characteristic, Consumer Interests Annual,2003,Vol,49:1-9

Millock, Katrin; Hansen, Lars Gårn[2002]:Willingness to Pay for Organic Foods: A Comparison between Survey Data and Panel Data from Denmark, Paper presented at Paper presented at the 12th annual EAERE (European Association of Environmental and Resource Economists) Conference, June 2002, Monterey, USA.

Verbeke, Wim, Scholderer, Joachim,and Frewer,Lynn[2006]:Consumer's perception of safety in the agri-food chain, Safety in the agri-food Chain, Wageningen Academic Publishers: p619-645

Tang, Ding na and Wan Hou fen[2003]: Green food and consumer behavior and psychology, paper presented at International conference” Food safety: consumer behavior, international trade and regulation"

Thompson, D.Gary, Kidwell, Julia[1998]:Explaining the choice of organic produce :cosmetic defects, prices, and consumer preferences, American Journal of Agricultural Economics,Vol.80,No.2,pp.277-287.

Wang, Zhi gang[2003]:The perception of food safety and purchase behavior- case from Tianjing, Journal of China Agricultural Economics, Vol.4:41-48

Yong Sook Eom[1994]:Pesticide residue and food safety valuation: A random utility approach, American Journal of Agricultural Economics,vol.76,pp760-771

Zeng Yinchu, XiaWei[2005]: Consumer’s Attitudes and Perception toward Green Food in Beijing, "Concordant Society and Development of Country", selected paper of national wide agricultural economist annual conference, China Agriculture Press,2005

Zhang, Xiao yong, Li, Gang and Zhang, Li[2004]: Chinese consumer's concern for food safety—case from Tianjing, Journal of China Rural Survey,Vol.1:14-21

Zhou, Jie hong[2004]: Consumer's attitude, perception and purchase behavior—case from Jiangsu province, Journal of China Agricultural Economics,vol.11:44-52

Zhou, Yingheng and Peng, Xiao jia[2006]: Consumer Willingness to Pay for Food Safety in Jiangsu Province , China Economic Quarterly, Vol.4: on pressing 